\title{
Environmental Impact Assessment of Tehran- Karaj Highway by Using Plants Indicators
}

\author{
Mustafa Nur Istanbuly ${ }^{1}$ Bahman Jabbarian Amiri ${ }^{*}$ Amir Hossein Hamidian ${ }^{3}$ \\ ${ }^{1,2,3}$ Department of Sciences \& Environmental Engineering, Faculty of Natural \\ Resources, University of Tehran \\ ${ }^{*}$ Corresponding author \\ istanbuly@ut.ac.ir $\quad$ jabbarian@ut.ac.ir $\quad$ a.hamidian@ut.ac.ir

\begin{tabular}{|l|l|l|}
\hline Submission date:- 1/4/2018 & Acceptance date:- 23/4/2018 & Publication date:- 16/7/2018 \\
\hline
\end{tabular}

\begin{abstract}
Lead pollution is one of the negative impacts of roads on environment, which can be assessed using environmental impact assessment. As a study case, Tehran- Karaj highway was selected for studying environmental lead pollution in pine tree needles (plants indicators). Samples were collected from seven stations and five distances $(0$, $10,20,50,100$ meter). The results showed that transport has a direct effect on lead pollution in trees. The differences in lead concentrations were significant for both stations and distances. The average lead concentration was $11.34 \mathrm{mg} / \mathrm{Kg}$ in the station close to Tehran, and $3.8 \mathrm{mg} / \mathrm{Kg}$ in the closest station to Karaj. This is because heavier transfer and higher density of cars in Tehran compared to Karaj. The average $\mathrm{Pb}$ concentrations in the stations besides the highway was $8.77 \mathrm{mg} / \mathrm{Kg}$ and decreased to $6.57 \mathrm{mg} / \mathrm{kg}$ in stations located in 100 meter away from the highway. While the average $\mathrm{Pb}$ concentration in station $\mathrm{E}$ was $1.53 \mathrm{mg} / \mathrm{Kg}$, it was decreased constantly in all distances, due to tree coverage. A conclusion, the analytical method of roads environmental impact assessment can be used effectively for monitoring $\mathrm{Pb}$ pollution. The pollution can be decreased by using pine trees and emphasis on using windbreakers.
\end{abstract}

Keywords: Environmental impact assessment, Lead pollution, Tehran- Karaj highway. 


\section{تقييم الأثر البيئي للطريق السريع طهران - كرج باستخدام المؤشرات النباتية}

\section{مصطفى نور استانبولي" $\quad$ بهمن جباريان اميري2" أمير حسين حميديان 3}

1,2,3 قسم علوم وهندسة البيئة، كلبة هندسة الموارد الطبيعبة، جامعة طهران

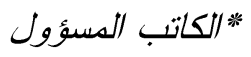

a.hamidian@ut.ac.ir jabbarian@ut.ac.ir istanbuly@ut.ac.ir

الخلاصة

إن التلوث بالرصاص من الآثار السلبية للطرقات على البيئة، والتي يمكن تقييمها باستخدام ثقييم الأثر

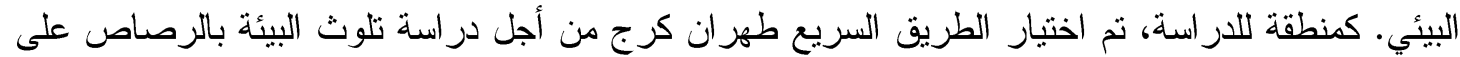

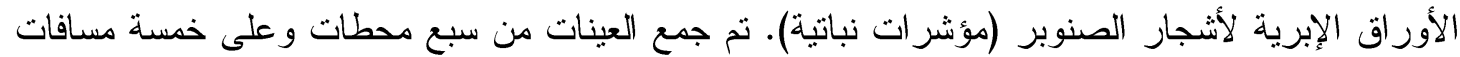

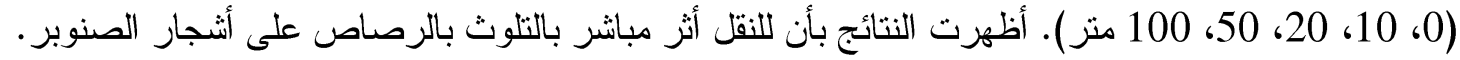

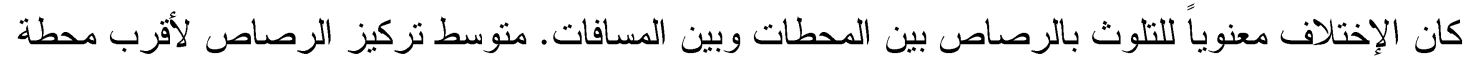

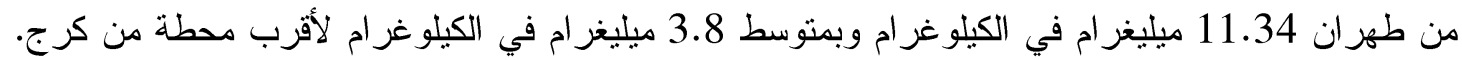

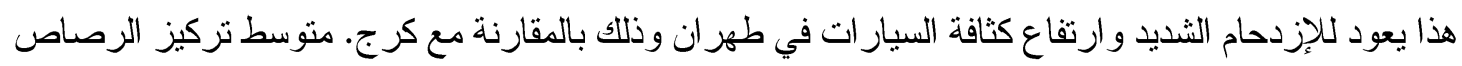

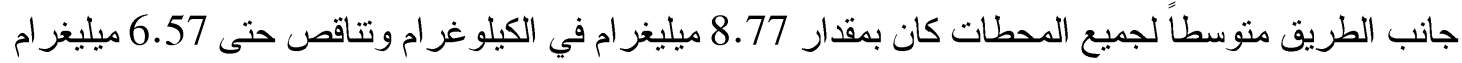
في الكيلوغر ام على المسافة 100 متر من حافة الطريق. بينما كان تركيز الرصاص للمحطة E 1.53 ميليغر ام في الكيلوغرام تناقص تركيز الرصاص بشكل ثابت على جميع المسافات وذلك بناء على التغطية الثجرية.

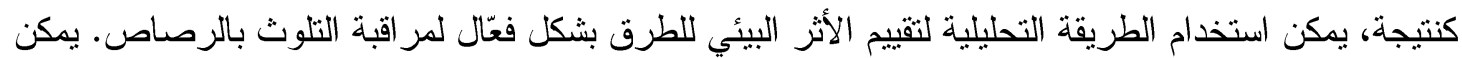
التقليل من التلوث بالرصاص باستخدام أثنجار الصنوبر و التأكيد على استخدام كاسرات الرياح. الكلمات المفتاحية: - تقييم الأثر البيئي، التلوث بالرصاص، طريق طهران كرج.

1

ساعد تثييد وبناء الطرقات الكبيرة خلال السنوات الأخيرة التتمية الصناعية و الزر اعية بشكل كبير،

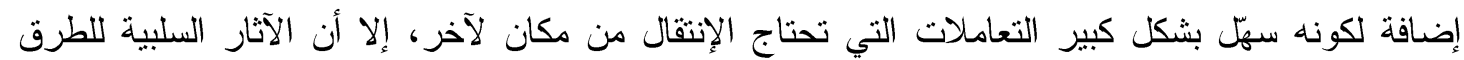

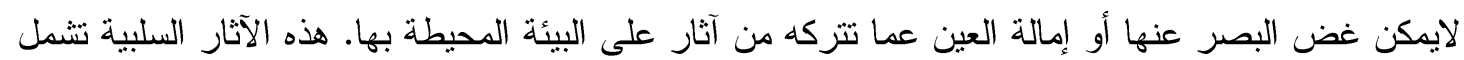
التلوث بالمعادن التقيلة أو بصورة أدق الملوثات السامة؛ كون اسم المعادن التقيلة هو اسم تم استخدامه على لهن نطاق واسع دون أي اساس علمي صحيح [1]. تتنقل هذه الملوثات عبر الهواء إلى التربة والماء و النباتات المحيطة بالطريق لتصبح جزءاً من السلسلة الغذائية، في النهاية سوف تصل هذه الملوثات إلى الانسان و الحيوان

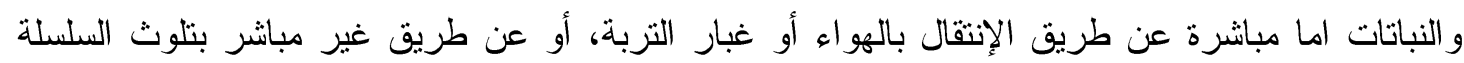

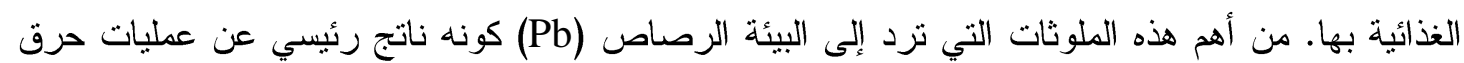


Journal of University of Babylon for Engineering Sciences, Vol. (26), No. (7): 2018.

الوقود الحاوي على الرصاص ضمن الآليات المنتقلة على الطرقات [2] [3] في عام 1994 ميلادي تم قياس وتسجيل 28390 طن من الرصاص في الجو ضمن المناطق المحيطة بالطرقات السريعة وفي ذلك الوقت امتلك

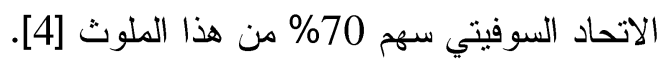

تركيز هذه الملوثات يكون بشكل كبير في المناطق المجاورة للطرقات بشكل مبانر ويقل هذا التركيز مع الابتعاد عن الحافة إلى الداخل بعيدا عن الطريق [5]. يرتبط تركيز الملوثات المنولدة عن الطرقات مباشرة بنوع الطريق إن كان رئيسيا أو فرعيا، كثافة الإزدحام على الطريق، عمليات تنظيم الطريق من إثنار ات المرور و التوقف و الحركة، عمليات التخريب: لسطح الطريق و ألوانه و الطلاء، إطارات السيارات، الفرامل. إضافة لإحتر اق و استهلاكك الزيوت المستخدمة لتسهيل حركة الأجزاء المتحركة في الآليات على الطريق [6]، [7]،

تشاهد الآثار البيئية للتلوث بالرصاص بشكل ملحوظ ضمن العشرة الأمتار الأولى من حافة الطريق

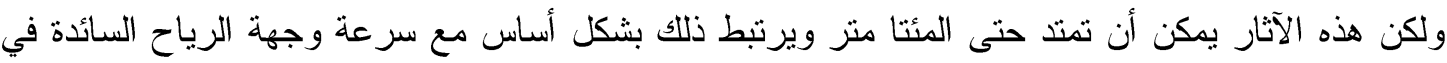
المنطقة المحيطة بالطريق وحسب كثافة الإزدحام على الطريق [9]، [10]. تؤثر الأنشطة البشرية كالصناعة، الزر اعة، البناء و استخدام الوقود الأحفوري بشكل كبير على دورة العناصر المعدنية في البيئة و الطبيعة؛ خاصة التي تسبب التلوث مثل الرصاص [11]. إن معدن الرصاص ينتشر بشكل رئيسي من الوقود المستخدم في لئي

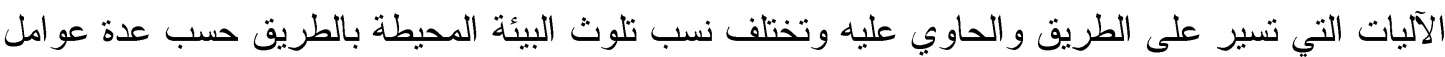
ذكرت سابقاً وأهها البعد عن حافة الطريق والإزدحام، هذا أدى لقلق كبير منذ عام 1970 حيث تم قياس ولت تز اكيز مرتفعة من الرصاص ناتجة عن حرق الوقود [12]. من الواجب ذكره أن التلوث الناتج عن الطرق

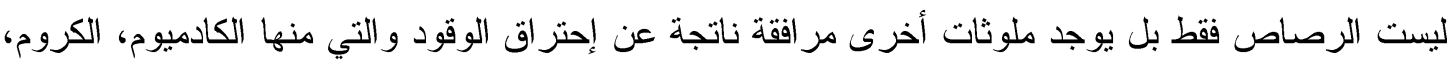

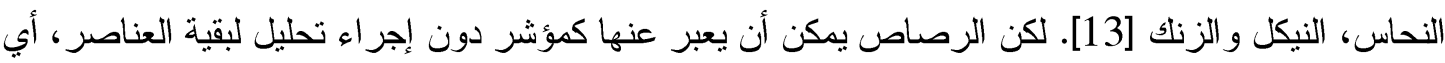

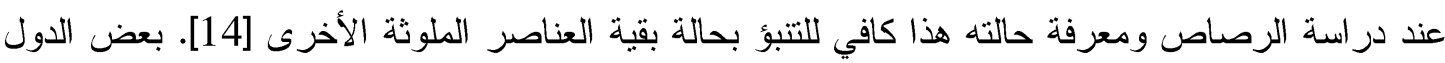
قامت باتخاذ إجر اءات مهمة للتخفيف من إنبعاث الرصاص الناتج عن حرق وقود السيار ات منذ أكثر من ثمانين

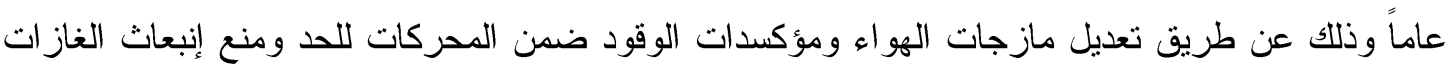
الافيئة وحماية الأوزون ومنع إنبعاث الرصاص ودئ فئلى البيئة المحيطة بالطرق [15]. يستطيع الرصاص الإنتقال عن طريق السلسلة الغذائية من التربة و النباتات إلى الإنسان إما بشكل مباشر

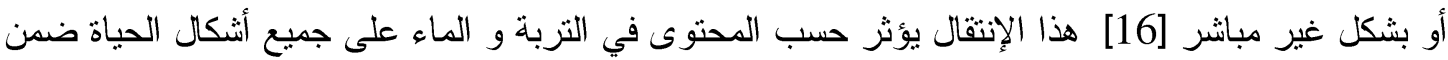
السلسلة الغذائية والتي تبدأ بالنباتات ؛ حيث يؤثر الرصاص على العمليات الحيوية فيها ويسبب نتوهات ألثناء الانقسامات الخلوية ، ومدى تأثثير الرصاص يرتبط بشكل كبير بتركيزه ضمن البيئة المحيطة و التي نتأثر بدورها

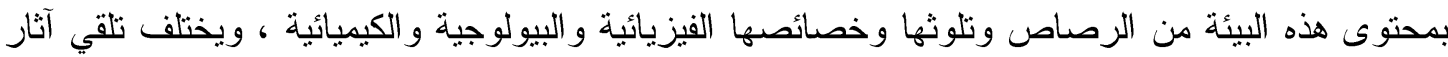
الملوثات ورد الفعل عليها حسب النوع المستقبل ونمط وظائفه الحيوية [11].

يعتبر تقييم الأثر البيئي أداة من أجل التنمية المستدامة لاتخاذ خطوات في سبيل معرفة الآثار الناتجة عن

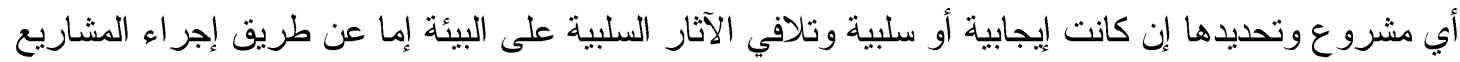
مع تعديلات أو تغييرات في شكل المشروع أو حتى إلغاء المشروع إن كانت آثاره خطيرة وغير قابلة الثيلة السيطرة و الجبران [18]، أما إن كان المشروع قد تم ووصل الى مرحلة الإستشمار كما في حالة الطريق السريع طهر ان ان 
Journal of University of Babylon for Engineering Sciences, Vol. (26), No. (7): 2018.

كرج ، فدور تقييم الأثر البيئي هنا هو تحديد الآثار السلبية والتتبيه لها لإتخاذ إجراءات تخفف منها أو تحمي

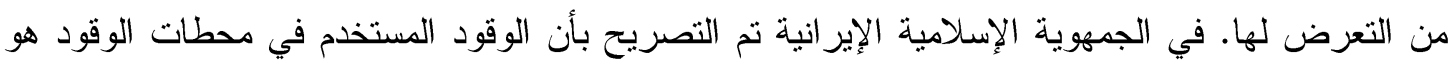

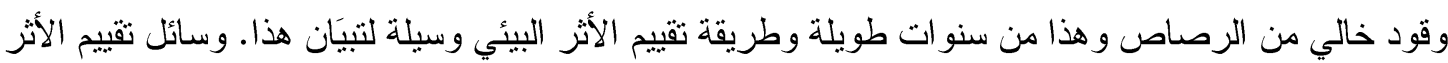

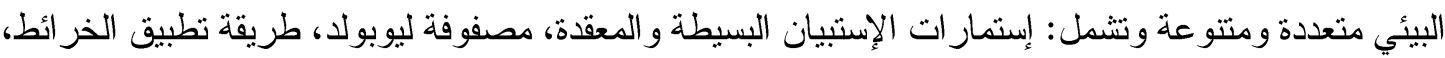

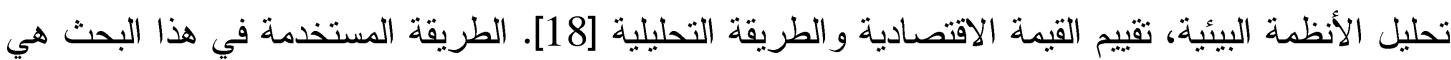
طريقة تقييم الاثر البيئي التحليلة والتي تقوم على مبدأ أخذ عينات من البيئة المحيطة وذلك على مسافات مختلفة

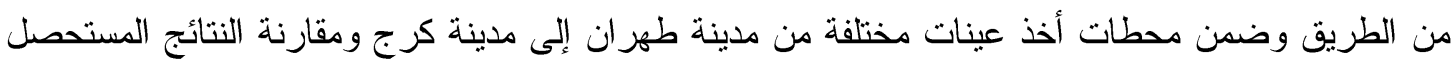

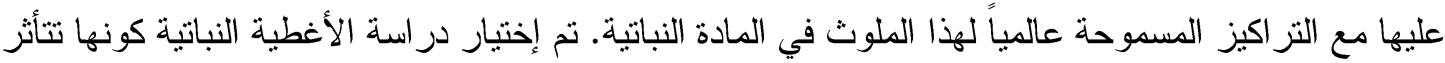
بالتلوث الناتج من الطريق بشكل مبانشر والمنتقل عبر الهواء والمستقر على أوراق النباتات، وتم إختيار شجر الصنوبر (Pine) كونه من إبريات الأوراق مستديمة الإخضرار ومتوسط عمر الأوراق سنتين تقريباً بالإضافة

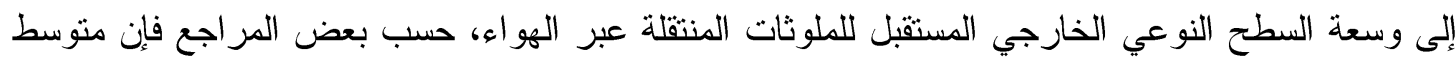
تركيز الرصاص ضمن أوراق الصنوبر غير المعرضة للتلوث وذات العمر سنة هو 0.2 ميليغرام في

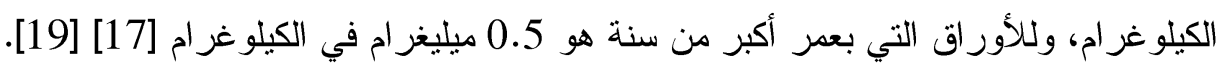

\section{2 2 البهف من البحث}

الهدف الرئيسي للبحث يكمن في تحديد مقدار التلوث بالرصاص للطريق على البيئة المحيطة؛ للطريق السريع الواصل بين العاصمة مدينة طهران ومدينة كرج وذللك بقياس التلوث بالرصاص الناتج عن استخدام

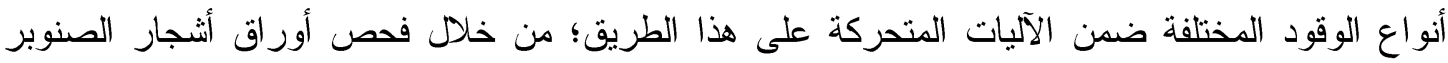

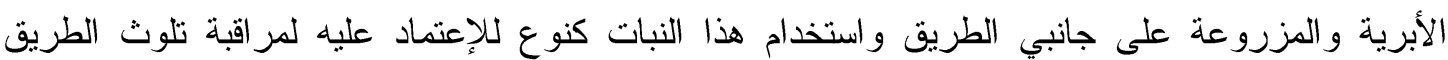
بالرصاص. من الأهداف الأخرى تحديد معنوية الإختلافات في التلوث بالرصاص على على طول الطريق من مدينة

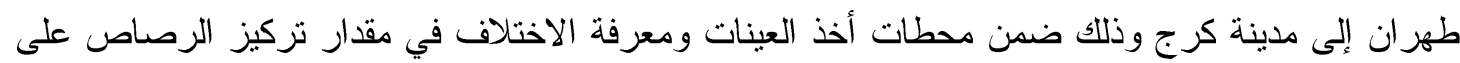
مسافات مختلفة من حافة الطريق لتحديد المنطقة المثالية الغير ملوثة.

3. - المو اد والأساليب

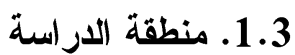

تقع منطقة الدر اسة على الطريق الرئيسي و السريع الو اصل بين مدينة طهران ومدينة كرج في الجمهورية

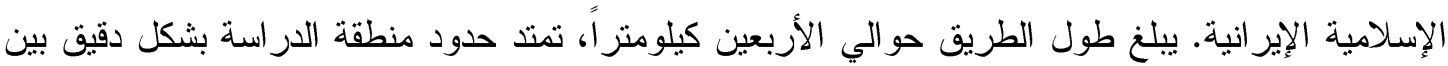

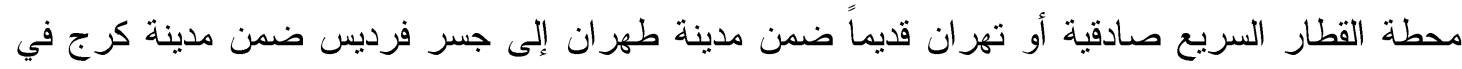

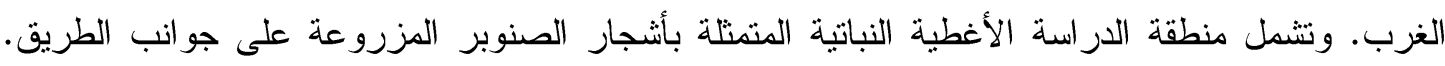

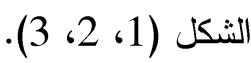




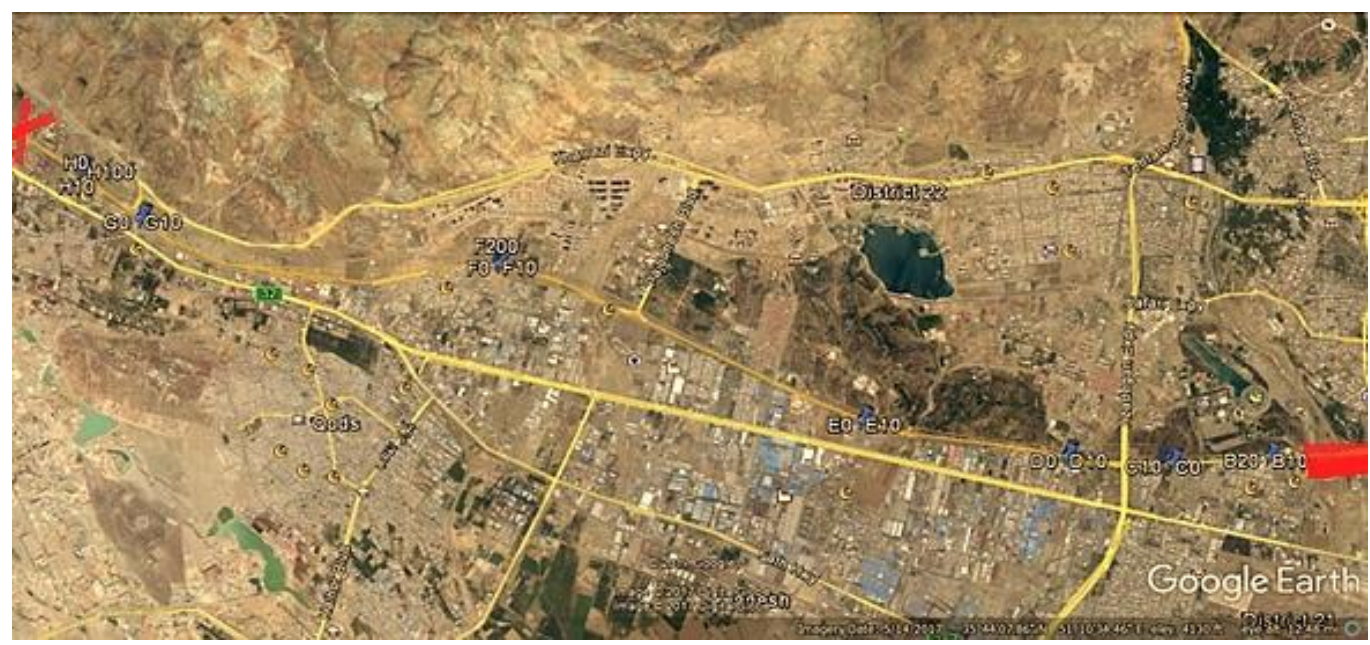

شكل (1): محطات أخذ العينات على طريق طهران كرج (طهران إلى يمين الصورة وكرج إلى يسار الصورة)

شرح الثنكل: يمتد طريق طهر ان كرج من يمين الثنكل إلى يساره بين العلامثنن الموضحتين وتظهر محطات أخذ العينات و التي تم تحديدها بو اسطة جهاز تحديد المو اقع العالمية، من اليمين و على الترتيب محطات أخذ العينات ( G - F - E - D - C -B

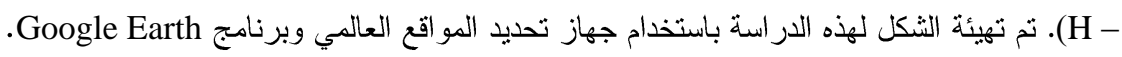

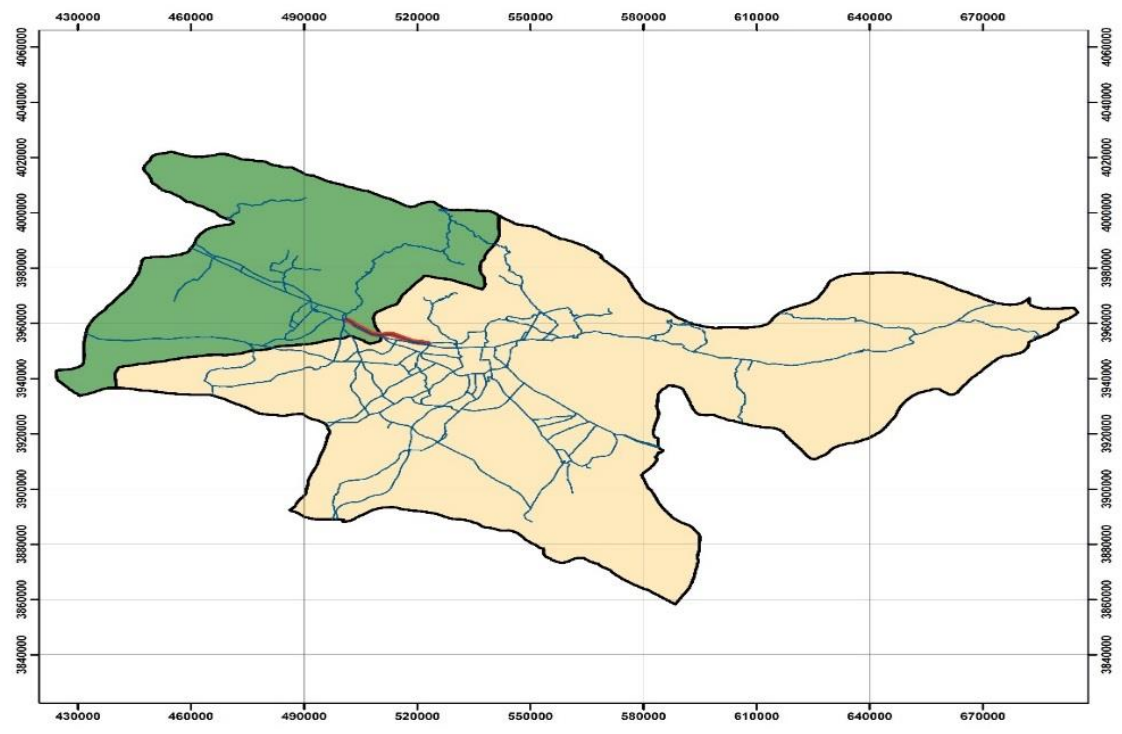

الثكل رقم (2): يبين الثنكل موقع الطريق الههم بين محافظة طهران و محافظة البرز التي يصل بينها طريق طهران كرج،

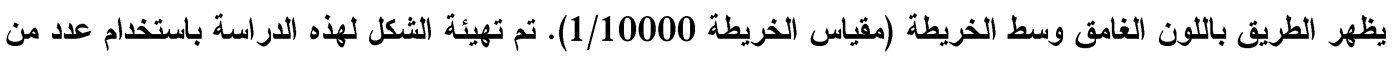
الخرائط المستحصل عليها من مديرية الغابات و تم تنظيمها و تعليلها بناء على احداثيات جهاز تحديد المواقع الجغرافية. 
Journal of University of Babylon for Engineering Sciences, Vol. (26), No. (7): 2018.

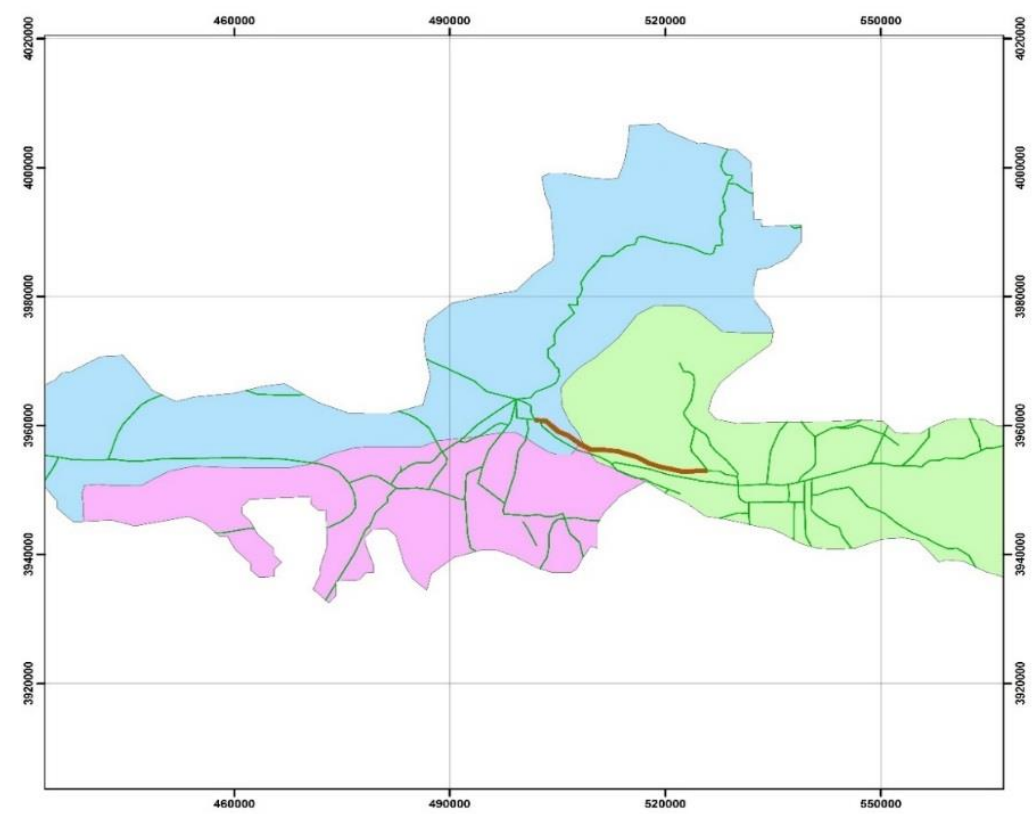

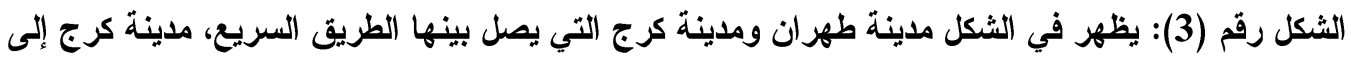

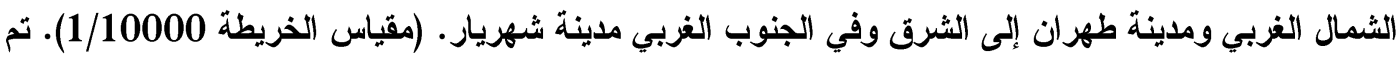
تهيئة الثنكل لهذه الدراسة باستخدام عدد من الخرائط المستحصل عليها من مديرية الغابات وتم تنظيمها وتعليلها بناء على احداثيات جهاز تحليد المو اقع الجغرافية.

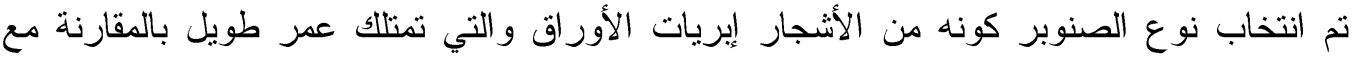

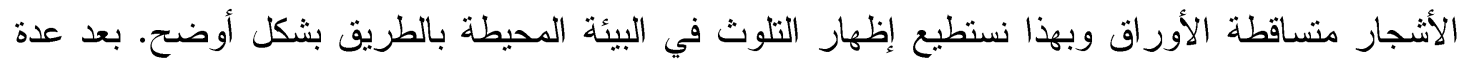
جو لات على مدار عام 2017 ميلادي وبعد قياس جهة الرياح الغالبة في المنطقة و التي كانت بعد موسم إنتهاء التهاء الأمطار في حزيران وخلال شهر حتى تموز جنوبية غربية (من جهة الجنوب الغربي إلى جهة الثمال الثرقي)؛

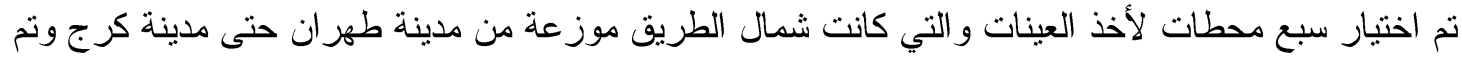

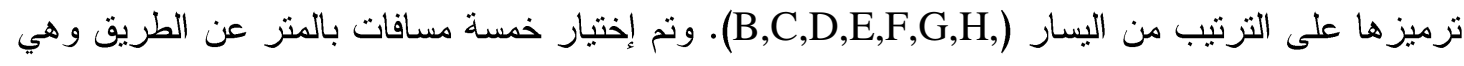

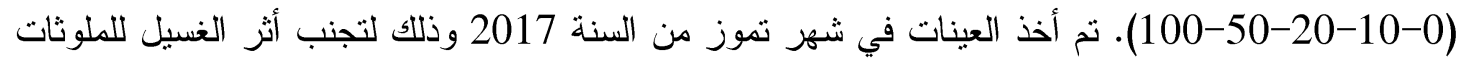
بو اسطة مياه الأمطار ولنكون العينات قدر الإمكان جافة [20]. أماكن محطات أخذ العينات تم انتخابها لنكون

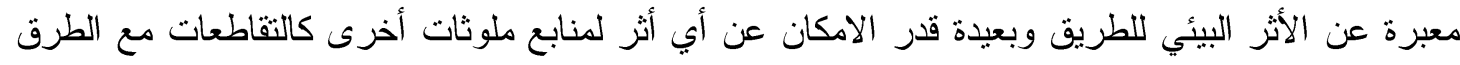
الأخرى، المناطق الصناعية والسكنية. أخذت العينات من أوراق الصنوبر (Pine sp. وذلك باستخدام مقص تقليم خاص و على ارتفاع الصدر ومن محيط كامل الثجرة وبشكل عثو ائي (Pinaceae)

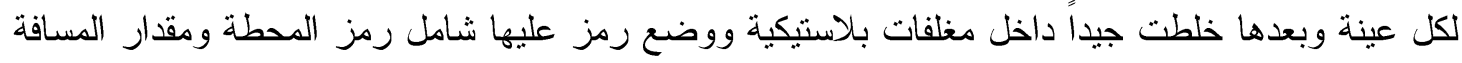
عن الطريق، ثم نقلت إلى المختبر وتركت لمدة ثلاثة أيام حتى تجف بشكل هو ائي [21]. 


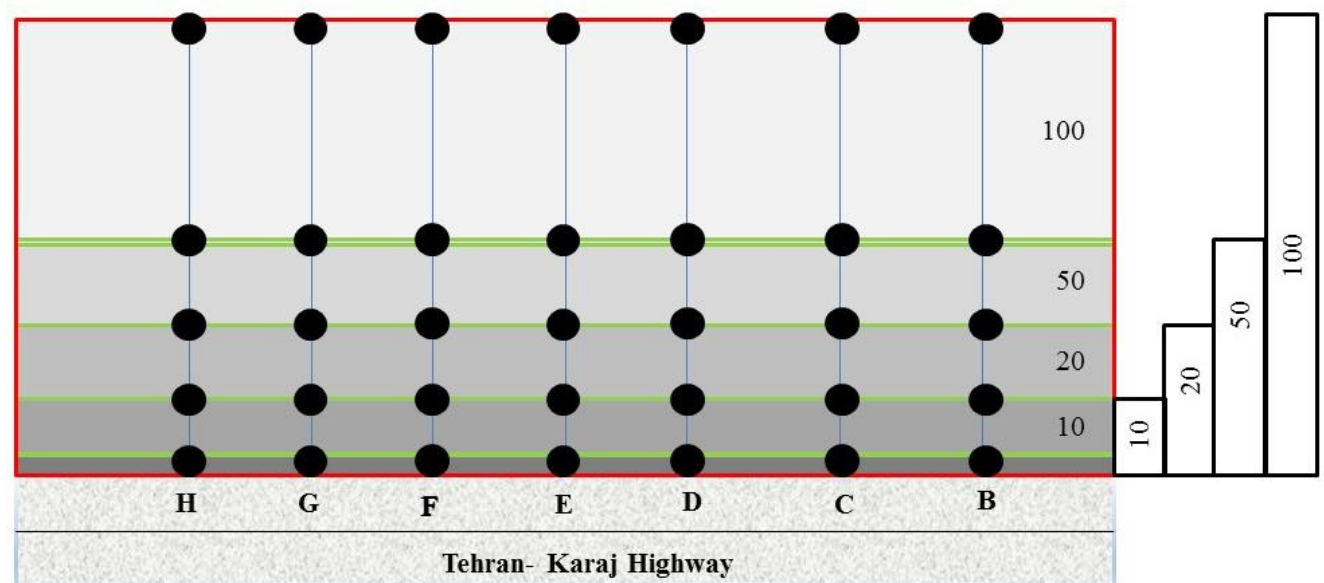

شكل رقم (4): طريقة توزيع مناطق أخذ العينات ضمن المحطات السوداء والمصفوفة بثكل عامودي على محور الطريق السريع طهران - كرج ترمز لمناطق أخذ العينات للمسافات

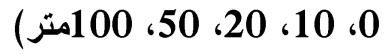

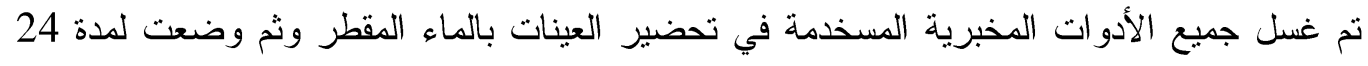

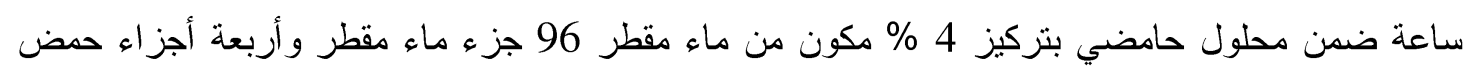
النتريك (HNO3)

لتحضير العينات نم إحضار أوعية من الخزف الصيني (بوتّقة) و التني وضعت بالمجفقة لمدة 12 ساعة ثم وزنت بعد التجفيف وسجل وزنها وهي خالية وبعدها تم وضع مقدار 2 غرام من العينات النباتية ضدن

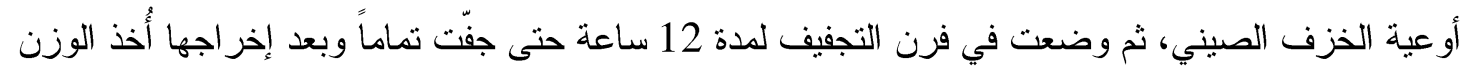
الجاف لها وذلك لحساب تركيز الرصاص بالميليغر ام في الكيلوغر ام من المادة النباتية الجافّة. في المرحلة التالية تم وضع العينات في الفرن على حر ارة 450 درجة مئوية وذلك للحصول على الرماد من المادة النباتبة الجافة؛

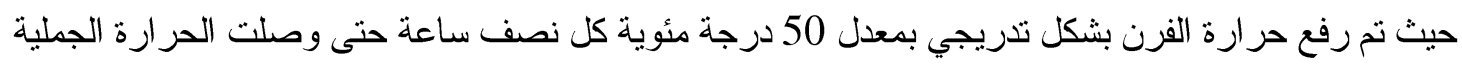
لحدود 450 درجة مئوية وأُقيت الحرارة على هذه الدرجة لمدة ساعتين، ذلك لمنع إحتراق العينات النباتية وتأكسدها وتحولها للون الأسود (تفحم العينات مما يسبب انخفاض في نوعية المحلول المُعد للمر احل التالية).

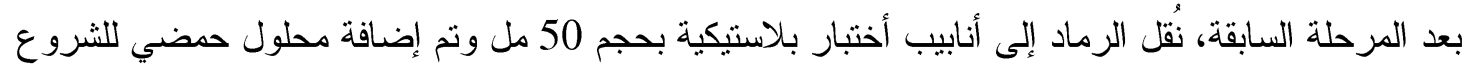

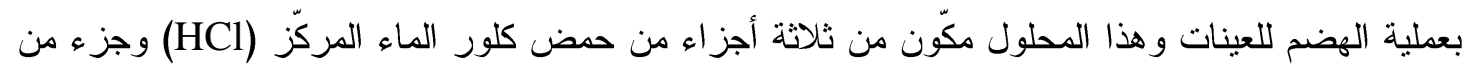

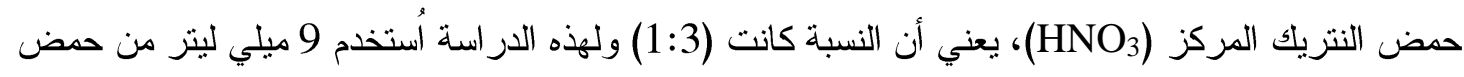
كلور الماء إلى 3 ميلي ليتز من حمض النتريك (هذا المحلول يدعى بالماء الملكي لإذابة جميع المعادن Rigea). تالياً وُضع المحلول الأسيدي الحاوي على الرماد المعدني في حمام مائي بحرارة 80 درجة مئوية

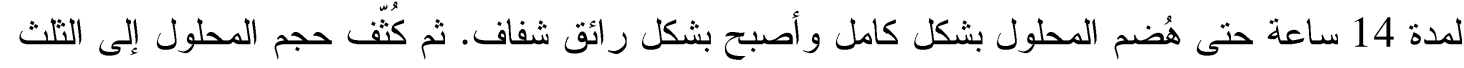
ورُفع من الحمام المائي ليتم بعدها تصفيته بو اسطة ورق فلترة من النوع (Chm-F2040) وذات الخواص (بطيئة سرعة التصفية، فتحات ذات قطر 7-9 ميكرومتر، محتوى رماد أقل من باستخدام بالونات زجاجية حجمية 50 ميلي ليتر نم زيادة حجم المحلول المستخلص إلى 50 ميلي ليتز بو اسطة

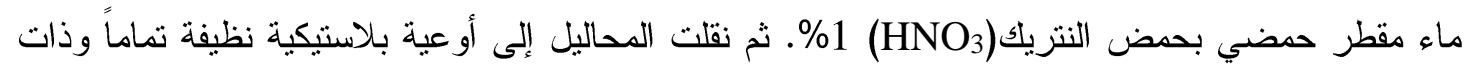
حجم 50 ميلي ليتز، ثم وضعت في البراد لحين إجراء تحليل نركيز معدن الرصاص فيها. 
Journal of University of Babylon for Engineering Sciences, Vol. (26), No. (7): 2018.

تم قياس تركيز معدن الرصاص ضمن المحاليل باستخدام جهاز الامنصاص الذري من النوع ( OSK 6564 ATOMIC ABSORPTION SPECTROPHOTOMETER OGAWA SEIKI co. LTD

\section{3.الطرق الإحصائية المستخدمة}

تم استخدام طرق الإحصاء الوصفي الثاملة على (المتوسطات، الوسيط، الوسط، الإنحر اف المعياري

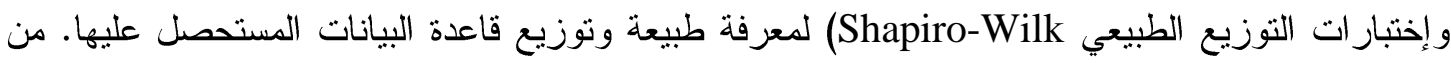
أجل معرفة الفروق المعنوية1 والإرنباطات2 و الروابط والنمذجة تم استخدام اختبار (- Kruskal-Wallis 1 way ANOVA لكون البيانات لا تتنمي إلى التوزيع الطبيعي3.

4. - المناقشة و النتائج

\section{4. تركيز الرصاص في محطات أخذ العينات على طول الطريق من طهران إلى كرج}

في الجدول رقم (1) و الثنكل رقم (5) نظهر نر اكيز الرصاص بالميليغر ام في الكيلوغرام وذلك بين المحطات المختلفة لأخذ العينات. أعلى متوسط تركيز للرصاص في المحطة الأولى القريبة من طهر ان بمقدار 11.34 ميليغر ام في الكيلوغرام و التركيز الأعلى التالي للمحطة التالية وهذا متوقع كون هذه لرهات المنطقتين الأكثر إزدحاماً لأنهما مدخل للعاصمة طهران. و وعلى العكس فإن أقل قيم كانت لآخر محطنين و القريبتان من مدينة

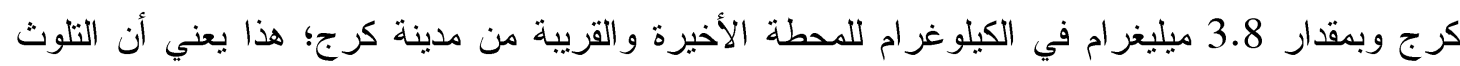
ينخفض بالإنتقال من مدينة طهران إلى كرج. طبعاً التركيز في المحطة الوسطى رقم 4 كان الأقل لكن هذه

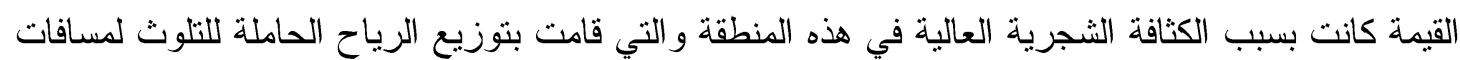

\begin{tabular}{|c|c|c|}
\hline صلص على نباتات محطات أخذ العينات & ) متوسط تركيز ) & جدول رقم (1) \\
\hline متوسط تركيز الرصاص (mg|Kg) & رمز المحطة & رقم المحطة \\
\hline 11.34 & B & 1 \\
\hline 10.19 & $\mathrm{C}$ & 2 \\
\hline 4.86 & $\mathrm{D}$ & 3 \\
\hline 1.53 & $\mathrm{E}$ & 4 \\
\hline 5.57 & $\mathrm{~F}$ & 5 \\
\hline 3.55 & $\mathrm{G}$ & 6 \\
\hline 3.80 & $\mathrm{H}$ & 7 \\
\hline
\end{tabular}

1 - Difference's significant

2 - Correlations

3 - normal distribution, also known as the Gaussian or standard normal distribution 
Journal of University of Babylon for Engineering Sciences, Vol. (26), No. (7): 2018.

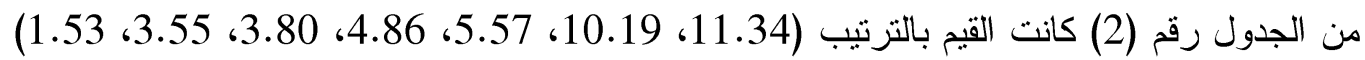

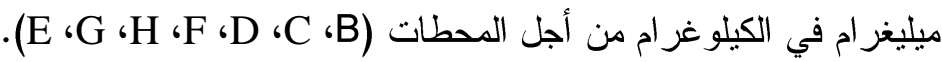

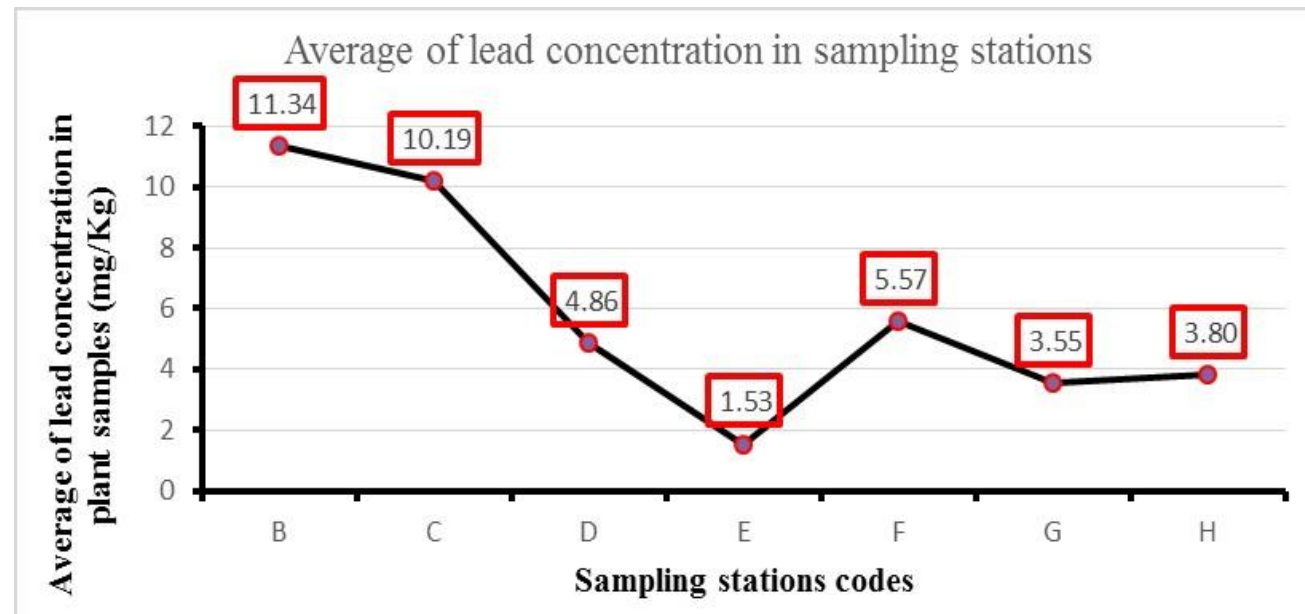

شكل (5): يُظهر المنحي في الثكل متوسط تركيز الرصاص المقاس في محطات أخذ العينات (متوسط لجميع

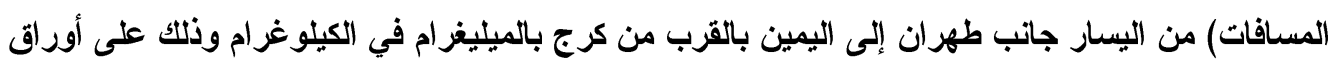
الصنوبر

2.4.تركيز الرصاص على مسافات مختلفة من حافة الطريق

بالنسبة للنتائج المسجلة لتزكيز الرصاص على مسافات مختلفة من طرف الطريق، إن الجدول رقم (2) و الثكل رقم (6) يحمل خلاصة عن ذلك ، ويظهر في هذا الجدول أنه تم تسجيل أعلى تركيز للفاصلة صفر أي للعينات المأخوذة مقابل الطريق مبانشرة وينقص هذا التزكيز مع زيادة المسافة وهذا دليل كافي بأن التلوث

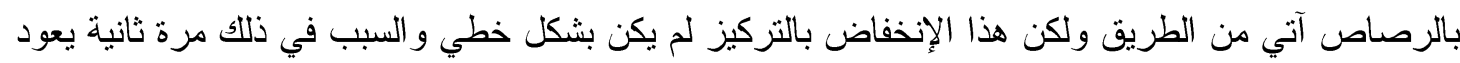

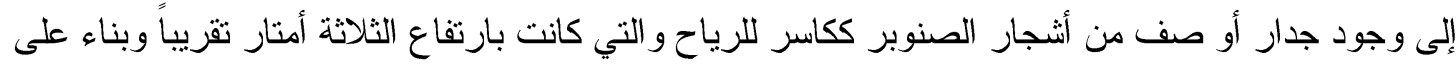

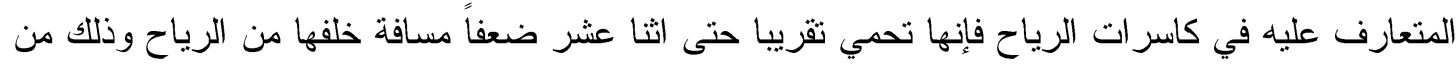

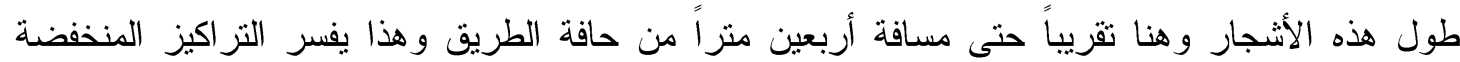

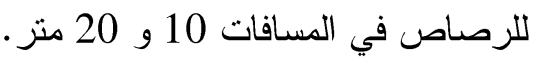

جدول رقم (2): متوسط تركيز الرصاص (كمتوسط لجميع المحطات) وذلك ضمن مسافات مختلفة عن

\begin{tabular}{|c|c|c|}
\hline \multicolumn{3}{|c|}{ الطريق } \\
\hline تركيز الرصاص (mg\Kg) & مقدار المسافة بالمتر & 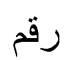 \\
\hline 8.77 & 0 & 1 \\
\hline 2.48 & 10 & 2 \\
\hline 4.06 & 20 & 3 \\
\hline 6.62 & 50 & 4 \\
\hline 6.57 & 100 & 5 \\
\hline
\end{tabular}


Journal of University of Babylon for Engineering Sciences, Vol. (26), No. (7): 2018.

من الجدول رقم (3) تراكيز الرصاص على الترتيب (8.77، 6.62، 6.57، 4.06،

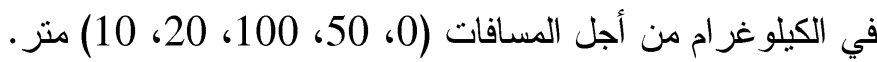

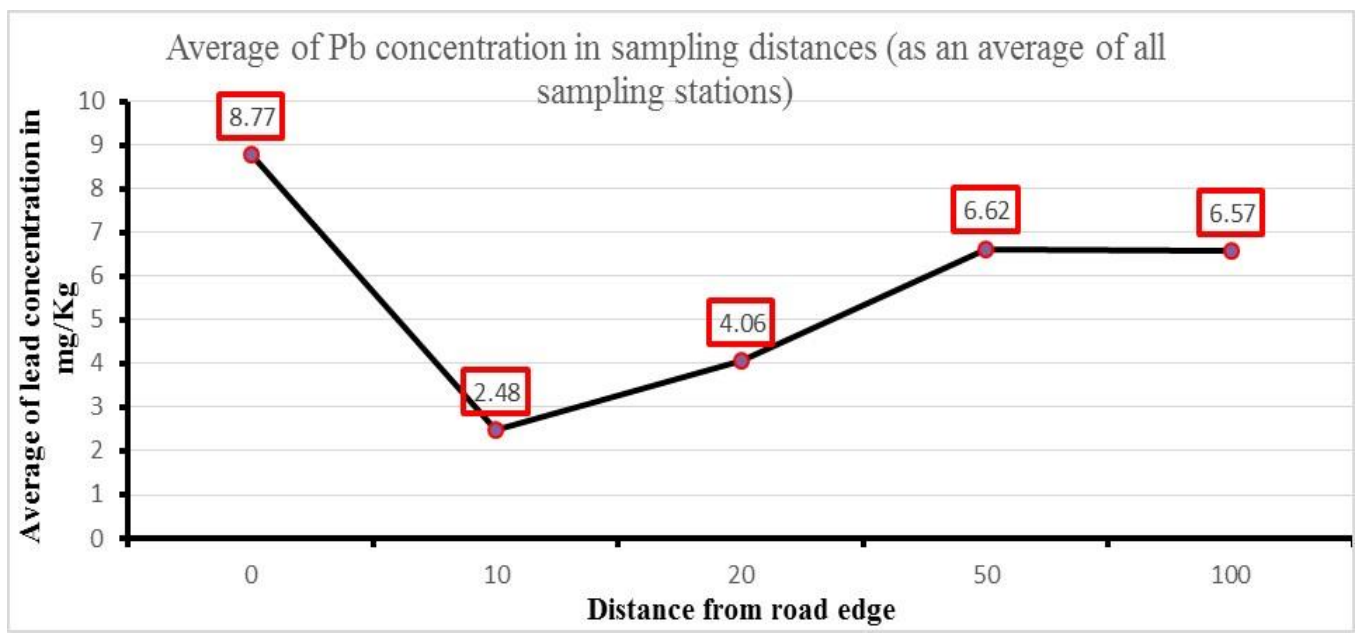

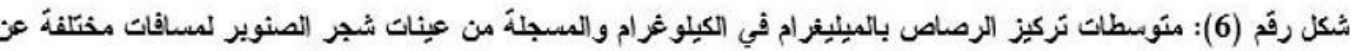

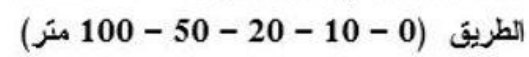

إن النتائج السابقة تحتاج للمقارنة مع مراجع عالمية وذللك لمعرفة إن كان أثر الطريق ضمن الحدود المقبولة أو تجاوز ها، و عند تجاوز الحدود الدقبولة يجب إتخاذ اجر اءات سريعة للحد من الأثار السلبية، الجدول

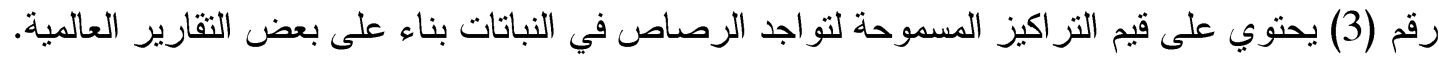

\begin{tabular}{|c|c|}
\hline \multicolumn{2}{|c|}{ جدول رقم (3)- التراكيز المسموحة لتواجد الرصاص في النباتات بناء على بعض التقارير العالمية } \\
\hline الحد الأعلى المجاز لتزكيز الرصاص في النباتات (mg/Kg) & المؤسسة صاحبة التقرير \\
\hline 10 & {$[23] \mathrm{EU}^{4} 2005$} \\
\hline 9 & [24] SEPA $^{5} 2005$ \\
\hline 2.5 & [25] PFA $2014^{6}$ \\
\hline $0.3-1$ & [26] $\mathrm{CODEX}^{7} 2014$ \\
\hline $20-100$ & $\begin{array}{c}\text { Kabata-Pendias \& Pendias } \\
{[19] 2010}\end{array}$ \\
\hline
\end{tabular}

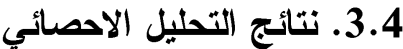

في البداية تم تحليل البيانات لمعرفة نوع التوزيع الإحصائي لها هل هو تابع للتوزيع الطبيعي او غير الطبيعي بإستخدام اختبار (Shapiro-Wilk) ، كانت النتيجة أن البيانات لا تنتع للتوزيع الطبيعي و كانت

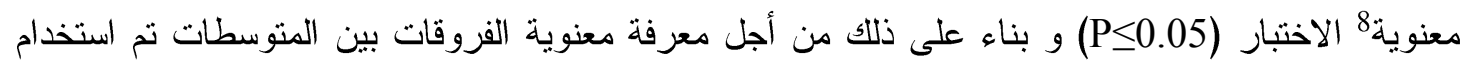

\footnotetext{
4 - European Commission (EU)

5 - State Environmental Protection Administration of China (SEPA)

6 - Prevention of food Adulteration Act Indian (PFA)

7 - CODEX Commission Alimentraius FAO

8 - P value of Significant
} 
Journal of University of Babylon for Engineering Sciences, Vol. (26), No. (7): 2018.

إختبار (Kruskal-Walis) للبيانات غير البار امترية (التي لا تتبع التوزيع الطبيعي) و النتائج كما نظهر في

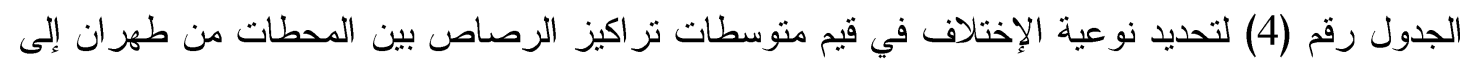

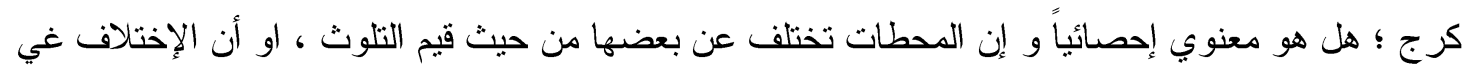

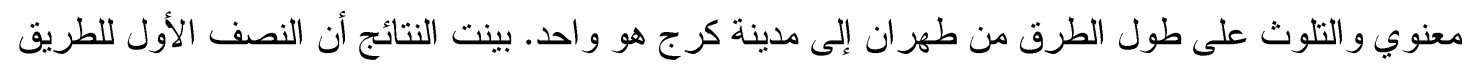

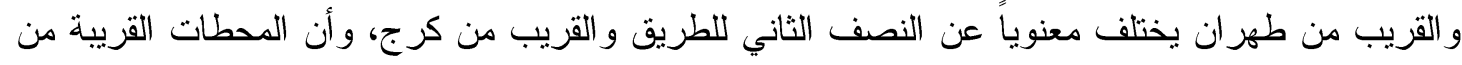

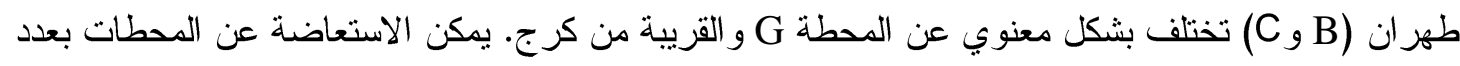
أقل من المحطات لمر اقبة مستويات التلوث على الطريق وذلك لتقليل التكلفة و الجهد، مثل الاستفادة من المحطنين

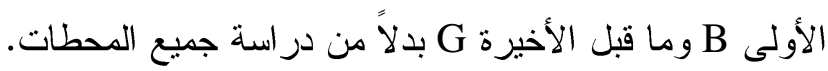

\begin{tabular}{|c|c|c|c|c|}
\hline \multicolumn{5}{|c|}{ جدول رقم (4): الفروق المغنوية بين متوسطات تركيز الرصاص المسجلة في محطات الدراسة } \\
\hline Sig $=\mathrm{P}$ & 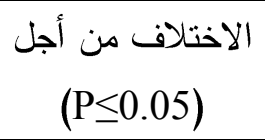 & المحطة & رقم المحطة & ترتيب الاختلافات المعنوية بناء \\
\hline 0.000 & معنوي & E-B & $4-1$ & 1 \\
\hline 0.002 & معنوي & E-C & $4-2$ & 2 \\
\hline 0.002 & معنوي & G-B & $6-1$ & 3 \\
\hline 0.038 & معنوي & G-C & $6-2$ & 4 \\
\hline 0.038 & معنوي & F-E & $5-4$ & 5 \\
\hline 0.038 & معنوي & $\mathrm{H}-\mathrm{B}$ & $7-1$ & 6 \\
\hline $0.05<$ & غير معنوي & - & المحطات & 7 \\
\hline
\end{tabular}

أما بالنسبة لتغيير ات المسافة عن حافة الطريق فأظهرت التحاليل الإحصائية أنه احصائياً لايوجد فرق

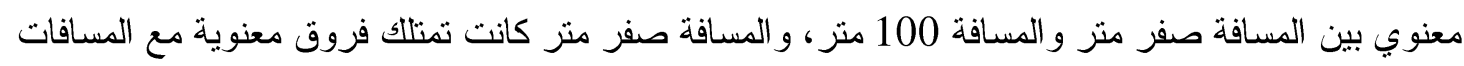

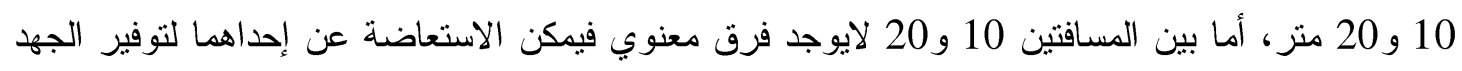

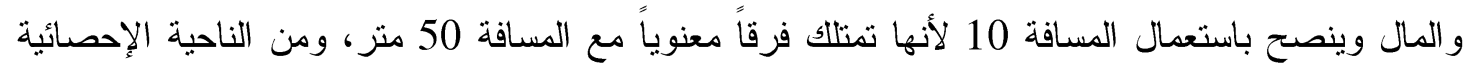

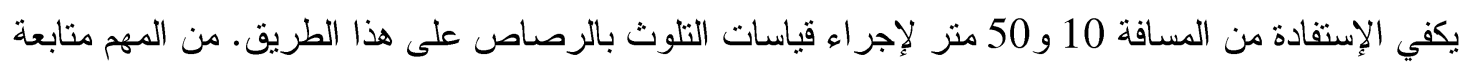
دراسة المسافات الأخرى حتى مسافة 200 متر و300 متر لمعرفة المدى الذي يصل إليه الأثر البيئي بالتلوث بالرصاص. 
Journal of University of Babylon for Engineering Sciences, Vol. (26), No. (7): 2018.

\begin{tabular}{|c|c|c|c|}
\hline \multicolumn{4}{|c|}{ جدول رقم (5): الفروق المعنوية بين تراكيز الرصاص المسجلة ضمن مسافات مختلفة عن حافة الطريق } \\
\hline $\mathrm{Sig}=\mathrm{P}$ & 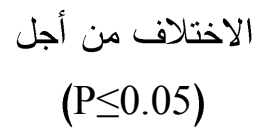 & مقدار المسافة & ترتيب الاختلافات المعنوية بناء على نتائج \\
\hline 0.000 & 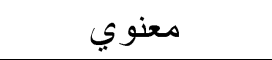 & $10-0$ & 1 \\
\hline 0.001 & 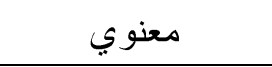 & $20-0$ & 2 \\
\hline 0.001 & 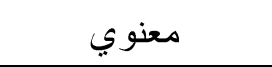 & $50-10$ & 3 \\
\hline $0.05<$ & غير معنوي & البقية & 4 \\
\hline
\end{tabular}

4.4. تحليل الإزتباط بين تركيز الرصاص للمحطات المختلفة وبُعد المسافة عن الطريق

تم إعتماد تحليل معامل الإرتباط 9 (Kendall's Tau-b) كون البيانات لا تتبع للتوزيع الطبيعي. أظهرت

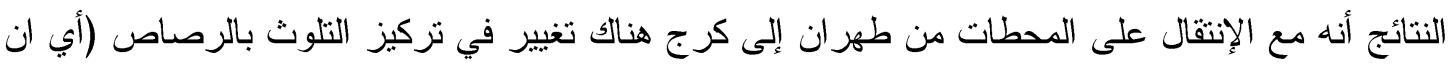
الاختلاف على طول الطريق ليس واحد وهناك رابطة خطية لهذا الاختلاف) وكانت قيمة معنوية الاختبار (P=0.01)

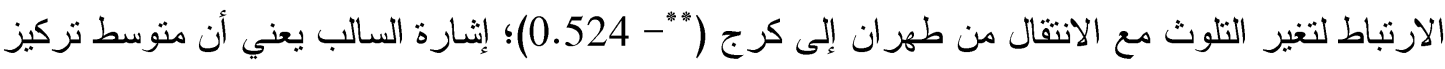

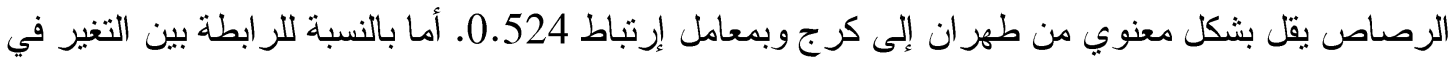

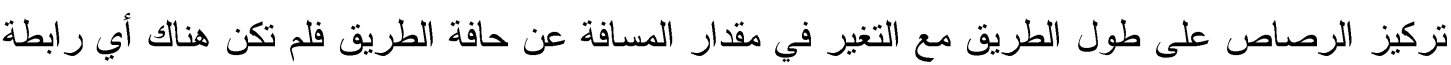
لهذا التغير وكل محطة تمنلك رابطة مختلفة عن الأخرى.

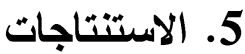

يلاحظ من النتائج أن النصف الاول من الطريق يحتوي على أكبر تركيز للرصاص بمتوسط مقداره

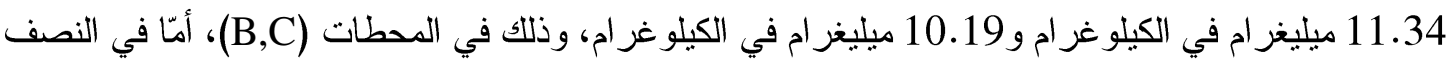
الثاني للطريق أبيّ باتجاه كرج فإن متوسط تركيز الرصاص هو أقل من النصف الأول. يمكن الإعتماد بناء

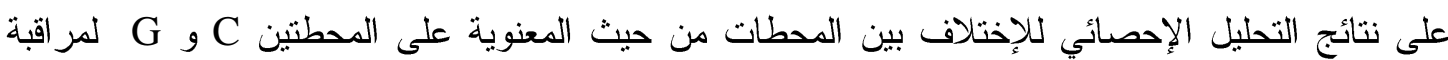
التلوث بالرصاص على الطريق وذلك لتوفير الجهد والمال الذي قد يكون كبيراً عند إجراء مراقبة لمستويات

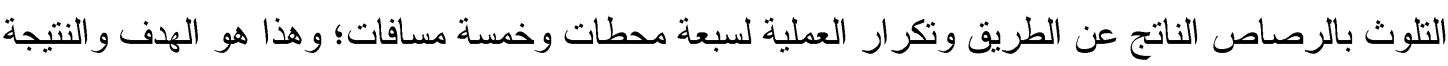

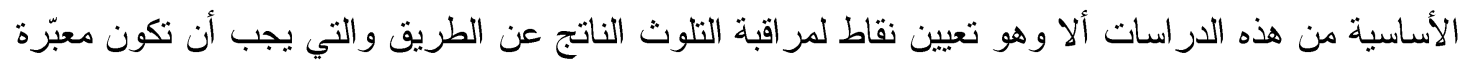
عن مقدار التلوث الفعلي وتوفر الجهذ والمال وبهذا يمكن الاستغناء عن النقاط الأخرى والإكتفاء بعدد أقل من فئن

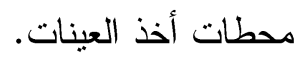

أقل تركيز للرصاص كان في المحطة (E) و التي إحتوت على أقل كثافة للغطاء العشبي العلفي و أكثر

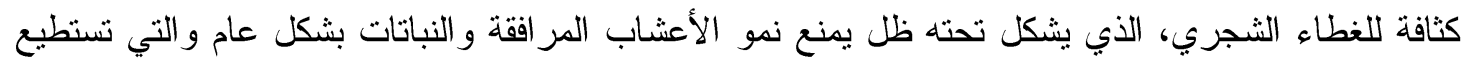
جذب الرصاص بواسطة جذورها والذي يبقى ضمن جذورها وأيضا نستطيع إمتصاص الرصاص المنتقل

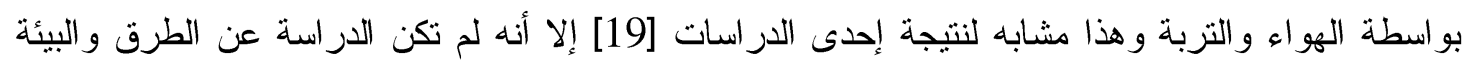
المحيطة بها وكانت تثبر فقط لاحتمال وجود رابطة بين عاملي الاختلاف في التغطية الثجرية ومتوسط تركيز

\footnotetext{
9 - Correlation factor
} 
Journal of University of Babylon for Engineering Sciences, Vol. (26), No. (7): 2018.

الرصاص على الأشجار، أما في هذه الدراسة قد ثبت أن هناك رابطة بين هذين العاملين وكلما زادت التغطية الثجرية قل متوسط نركيز الرصاص على الثجرة الواحدة والسبب في ذلك نوزيع الرياح المحملة بالملوثات على أثجار أكثر ومسافات أكبر ، بالاضافة لما تم ذكره فإن جدار من الأثجار يستطيع كسر الرياح وحماية 10 إلى 15 ضعف مقدار ارتفاعه لمسافة خلفه من الأرض وإن كان هذا الجدار مشكل من صفين فإن هذه المسافة الهن

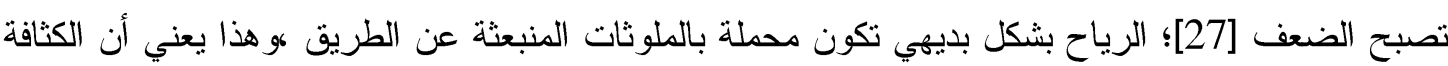

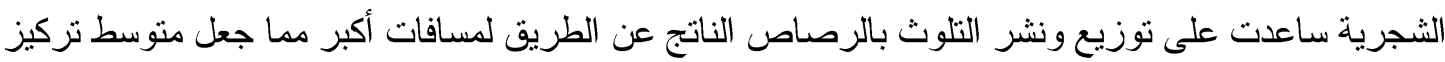
الرصاص منخفض في نقاط الدراسة وفي المناطق التي أمتلكت صف من الأشجار مما ساعد على حماية المناطق التي تقع خلفها من التلوث ( المسافة 10 و 20 منر عن حافة الطريق).

بالنسبة لمتوسط تركيز الرصاص للمحطات وعلاقته بتغير المسافة عن حافة الطريق؛ إمتلكت المسافة صفر أو المنطقة المواجهة للطريق بشكل مباثر على أعلى تركيز للرصاص 8.77 ميليغرام في الكيلوغرام،

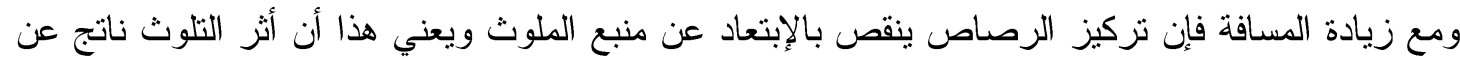

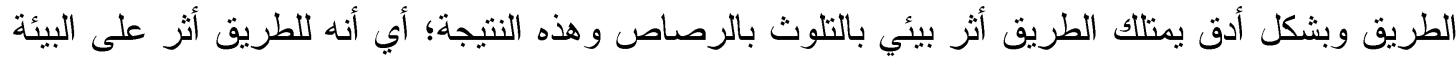

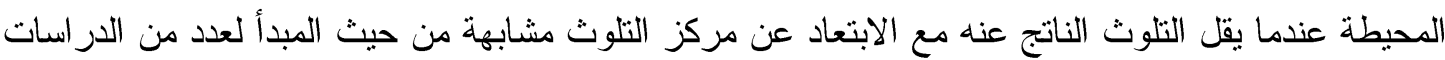

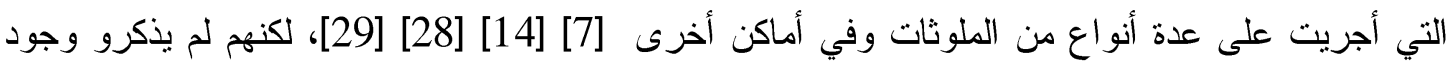
عو امل أخرى تؤثر على أختلاف متوسط تركيز الملوثات مع التغير في المسافة؛ كالكثافة الثجرية مثلاً. تفسير ودر اسة نتائج التحليل الاحصائي أظهرت أن منوسط تركيز الرصاص بين المسافتين 0-10 امتلك أعلى قيمة اختلاف معنوي ويأتي بعده الأختلاف في متوسط الرصاص للمسافات 0-20، 10-50 متر ، أما الفرق بين المسافتين 10 و20 غير معنوي أي لايوجد اختلاف من الناحية الاحصائية بين المتوسطين

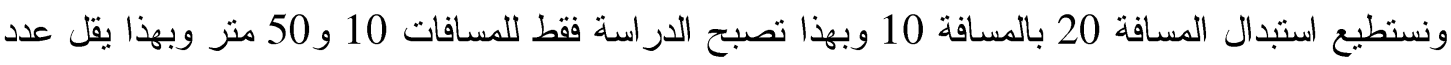
النقاط المخصصة للمر اقبة التالية لمستويات التلوث الناتجة عن الطريق، مع هذه النتيجة هنالك توفير للجهد و التكلفة كون المر اقبة سوف تتحصر في عدد أقل من المسافات الواجب اجر اء تحليل لها.

كخلاصة تقييم الأثز البيئي للطريق السريع طهران كرج على البيئة المحيطة به؛ يمتلك الطريق تأثثر سلبي على البيئة المحيطة به، ذلك بالتلوث بمعدن الرصاص الناتج عن حرق الوقود المستخدم في الآليات المنتقلة على الطريق. إن أعلى منوسط تركيز للرصاص قد نم قياسه للفاصلة الأولى عن الطريق وبمقدار

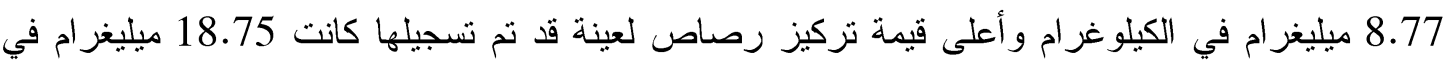
الكيلوغر ام؛ بالمقارنة مع المسموح عالمباً، إن هذه القيم قد تجاوزت الحدود المسموحة (جدول رقم 3. 3). وبناء على عينات نباتية فإن هذه النسبة قد تجاوزت بشكل كبير الحد الطبيعي بناء على الدراسات الدذكورة لكاباتا بندياز [19]، هذا يعكس أن الوقود المسخدم يحتوي بشكل مؤكد على الرصاص لثان رغم التأكيد على أن الوقود الموجود حالياً خالي تماماً من الرصاص. بناء على هذه الدراسة لودة يمكن القول إنه للطرق آثار سلبية على البيئة

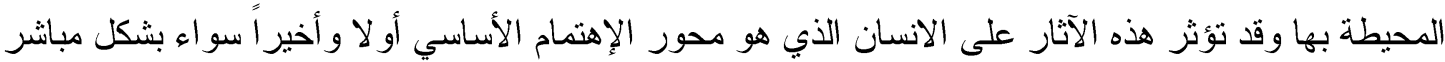

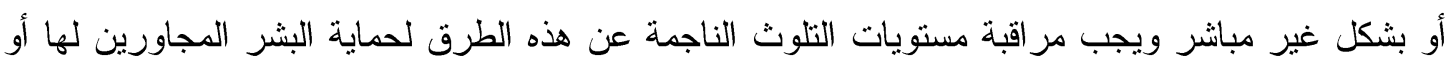

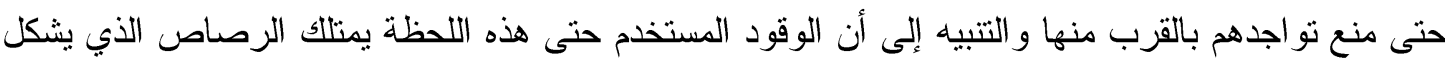
تهديداً حقيقياً على صحة البيئة المجاورة للطرق خاصة الكبيرة و السريعة منها. 


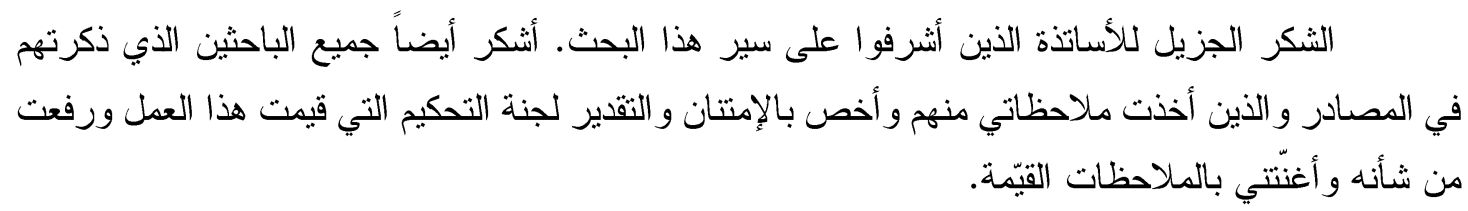

\section{References}

[1] Duffus J. H., "Heavy metals-A Meaningless Term", pure and applied chmistry, vol. 74, no. 5, p. 793-807, 2002.

[2] Nabulo G., Oryem-Origa H. and Diamond M., "Assessment of lead, cadmium and zink contamination of roadside films and vegetables in kampala city, uganda," Environmental Research, vol. 101, no. 1, pp. 42-52, 2006.

[3] Preciado H. F., Li L. Y. and Weis D., "Investigation of past and present multimetal input along two highways of British Columbia, Canada, using lead isotopic signatures.," Water, Air, and Soil Pollution, vol. 184, no. 1-4, p. 127-139, September 2007.

[4] Gromov S. and Emelina E., "Lead emission evaluation over the European part of the former Soviet Union," Science of The Total Environment, vol. 158, p. 135137, 18, December 1994.

[5] Sezgin N., Ozcan H. K.,Demir G., Nemlioglu S. and Bayat C., "Determination of heavy metal concentrations in street dusts in Istanbul, E-5 highway," Environment International, vol. 29, no. 7, p. 979-985, January 2004.

[6] Sutherland R. and Tolosa C., "Multi-element analysis of road-deposited sediment in an urban drainage basin, Honolulu, Hawaii," Environmental Pollution, vol. 110, no. 3, p. 483-495, December 2000.

[7] Werkenthin M., Kluge B. and Wessolek G., "Metals in European roadside soils and soil solution - A review," Environmental Pollution, vol. 189, pp. 98-110, June 2014.

[8] Thorpe A. and Harrison R. M., "Sources and properties of non-exhaust particulate matter from road traffic: A review," Science of The Total Environment, vol. 400, no. 1-3, p. 270-282, August 2008.

[9] Bignal K. L., Ashmore M. R., Headley A. D., Stewart K. and Weigert K., "Ecological impacts of air pollution from road transport on local vegetation," Applied Geochemistry, vol. 22, no. 6, p. 1265-1271, June 2007.

[10] Bernhardt-Römermann M., Kirchner M., Kudernatsch T., Jakobi G. and Fischer A., "Changed vegetation composition in coniferous forests near to motorways in Southern Germany: The effects of traffic-born pollution," Environmental Pollution, vol. 143, no. 3, p. 572-581, October 2006.

[11] Bashkin V., Biogeochemical cycling of trace elements, Dordrecht ed., Moscow State UniversityRussia: Springer, Dordrecht, p. 161-197, 2002. 
[12] Van Bohemen H. and Van De Laak W., "The influence of road infrastructure and traffic on soil, water, and air quality," Environmental management, vol. 31, no. 1, p. 0050-0068, Jan 2003.

[13] Münch D., "Content profiles of arsenic, cadmium, chromium, copper, lead, mercury, nickel, zinc, vanadium and polynuclear aromatic hydrocarbons (PAH) in forest soil beside an urban road," Science of The Total Environment, vol. 138, no. 1-3, p. 47-55, 30 September 1993.

[14] Zhang H., Wang Z., Zhang Y., Ding M. and Li L., "Identification of trafficrelated metals and the effects of different environments on their enrichment in roadside soils along the Qinghai-Tibet highway," Science of the Total Environment, vol. 521-522, p. 160-172, July 2015.

[15] Courtney W., Rheingrover S., Pilotte J., Kaufmann H., Cahill T. and Nelson J., "Continuous observation of particulates during the general motors sulfate dispersion experiment," J. Air Pollut. Control Assoc., vol. 28, no. 3, p. 225-228, 1/3/ 1978 .

[16] Adelasoye K. and Alamu L., "Accumulation of heavy metal pollutants in soil and vegetation and their effects on soil microbial population on roadsides in Ogbomoso, Nigeria," Journal of Environmental Science and Water Resources, vol. 5 , no. $1,2016$.

[17] Kabata-Pendias A. and Pendias H., Trace Elements in Soils and Plants, Boca Raton London New York Washington, D.C: CRC Press, 2001.

[18] Jabbarian Amiri B., Environmental Impact Assessment, Tehran: Tehran Press. 3469, 2014.

[19] Kabata-Pendias A., Trace elements in soils and plants, Fourth Edition, Boca Raton United States of America: CRC Press, 2011.

[20] Tamuly P. and Devi A., "Heavy metal contamination of roadside topsoil in some areas of Golaghat and Jorhat district along national highway-37, Upper Assam, India," INTERNATIONAL JOURNAL OF ENVIRONMENTAL SCIENCES, vol. 5, no. 2, pp. 472-481, 2014.

[21] Swaileh K., Hussein R. and Abu-Elhaj S., "Assessment of heavy metal pollution in roadside surface soil and vegetation from the West Bank," Archives of Environmental Contamination and Toxicology, vol. 47, no. 1, pp. 23-30, Jul 2004.

[22] Chmlab Group, Filtration \& microfiltration new possibilities in filtration, Barcelona-spain: Chmlab Group, 2017.

[23] Anonymous, "Reportes 87/EC of 5 December. European Commission Directive," European Union, Commission of the European Communitie, 2005a.

[24] Anonymous, "The Limits of Pollutants in Food," State Environmental Protection Administration of China, Beijing, China, 2005c. 
Journal of University of Babylon for Engineering Sciences, Vol. (26), No. (7): 2018.

[25] Anonymous, "The Prevention of Food Adulteration Act \& Rules," Prevention of Food Adulteration Act Indian, india, 2014.

[26] Anonymous, "Contaminants. CODEX Alimentarius Commission," Joint FAO/WHO Food Standards Program, Rome, Italy, 2014.

[27] Wilson J. S. and Josiah J., "Windbreak Design," NebGuide, University of Nebraska-Lincoln Extension- Institue of Agriculture and Natural Resources, vol. G1304, p. G1304, march 2004.

[28] Yan X., Gao D., Zhang F., Zeng C., Xiang W. and Zhang M., "Relationships between Heavy Metal Concentrations in Roadside Topsoil and Distance to Road Edge Based on Field Observations in the Qinghai-Tibet Plateau, China," Environmental Research and Public Health, vol. 10, no. 3, pp. 762-775, Mar 2013.

[29] Guo G., L. M, C. T, S. B and L. X, "Effect of road traffic on heavy metals in road dusts and roadside soils," Huanjing Kexue Xuebao / Acta Scientiae Circumstantiae, vol. 28, no. 10, pp. 1937-1945, October 2008. 